\title{
ЯЗЫКОВАЯ ЛИЧНОСТЬ КАК ОБЪЕКТ ЛИНГВОПЕРСОНОЛОГИИ
}

\section{С Л. Р. Шамсутдинова}

\author{
Башкирский государственный университет \\ Россия, Республика Башкортостан, 450076 г. Уфа, ул. Заки Валиди, 32. \\ Тел.: +7 (347) 2727463 . \\ Email: Muliya2814@gmail.com
}

\begin{abstract}
Целью данной статьи является рассмотрение феномена языковой личности как основного объекта современного научного направления - лингвоперсонологии - в иентре изучения которого находится языковая личность во всем ее коммуникативном многообразии.

Основное внимание уделено специфике современной языковой личности, ее становлению, а также анализу существующих классификаиий указанного языкового феномена. Выявлены типологии языковых личностей, рассмотрены качественные признаки в рамках трех существенных характеристик (вербально-семантическая, когнитивная, прагматическая); выделены компоненты в содержании языковой личности (мировоззренческий, культурологический, личностный) и указано на объективные факторы, определяющие ее характер.
\end{abstract}

Ключевые слова: антропоцентризм, лингвоперсонология, парадигма, языковая личность, тип языковой личности, классификация, коммуникативная ситуация.

Понятие языковой личности является одним из центральных в современном языкознании. Внимание к феномену языковой личности во многом обусловлено интересом лингвистов к антропоцентрической парадигме. Прежде чем перейти к характеристике данной парадигмы и трактовке языковой личности, рассмотрим одно из важнейших понятий языкознания - «научная парадигма».

Термин «парадигма» упоминается в трудах Ф. де Соссюра, под которым он понимал систему форм одного и того же слова [24]. Позднее, в 1962 г.. выходит в свет широко известная книга американского ученого Т. Куна «Структура научных революций», где впервые упоминается термин «парадигма научного знания». Он предложил понимание парадигмы как некоторой совокупности знаний и особенностях подхода к объекту исследования, т.е. к языку [19].

Е. С. Кубрякова, анализируя понятие парадигмы знания, выделяет три звена в ее структуре: установочно-предпосылочное, предметно-познавательное, процедурное. Первое звено связано с некими условиями возникновения исследования, которые зависят от культурной традиции страны и времени. Второе относится непосредственно к предметной сфере анализа: это единицы исследования, область исследования, применяемые подходы. К третьему звену Е. С. Кубрякова причисляет методики анализа [18]. Парадигма воплощает в себе бесспорное общепризнанное знание об исследуемой области явлений.

Полагаем, что термин «научная парадигма» может иметь следующую расшифровку: научная парадигма - это совокупность представлений и убеждений ряда ученых, разработки и теории которых признаются научным сообществом и являются ведущими в определенной области знания в течение некого промежутка времени. В рамках тех или иных представлений, убеждений, теорий ученый исследует проблему или ряд проблем. Научная па- радигма предполагает методы решения этих проблем. Стоит отметить, что на определенном временном промежутке парадигма имеет общепризнанный характер. Так, языкознание девятнадцатого столетия прошло под эгидой сравнительноисторической парадигмы.

Многие ученые (В. А. Маслова, Н. Ф. Алефиренко, Е. С. Кубрякова, А. В. Кравченко, М. В. Пименова и др.) выделяют три научные парадигмы сравнительно-историческаую, системно-структурную и антропоцентрическую, господствовали или господствуют в определенный период истории науки о языке.

По мнению Е. С. Кубряковой, антропоцентризм тесно связан с другим «главным параметром современной лингвистики» - функционализмом, следовательно, правомерным считается отнесение к лингвистическому антропоцентризму когнитивного и коммуникативного направлений [18, с. 187].

Другой выдающийся исследователь Ю. Н. Караулов выделяет историческую, психологическую, системно-структурную и социальную парадигмы. По мнению ученого, антропоцентрическое направление выделяется в рамках социальной парадигмы наряду с когнитивным, психолингвистическим, лингвокультурологическим и социолингвистическим [13].

«Идея антропоцентричности языка - ключевая в современной лингвистике», - пишет В. А. Маслова $[21$, с. 11]. Вполне очевидно, что идея антропоцентризма, связанная с важнейшим для любой области знания понятием человека, не могла зародиться только в XX в. Истоки этой идеи прослеживаются еще в трудах В. фон Гумбольдта, Э. Бенвениста и Ф. де Соссюра.

«Язык является основным средством описания и познания внешнего мира и психики самого человека. Личность прежде всего отражается в языке, а язык, в свою очередь, - это зеркало человеческой 
души, поэтому огромный интерес представляет собой человек как языковая личность» [25].

В современных научных исследованиях предлагаются различные определения понятия «языковая личность», что связано с «антиномичностью исходных объектов, отраженных в рассматриваемом словосочетании (единство и противоположность языка/речи, социального и индивидуального начала в человеке) и недостаточной сформированностью терминологического аппарата новой области научного знания - лингвоперсонологии» $[11$, с. 31$]$.

История возникновения термина «языковая личность» и активизация его использования в языке современной лингвистической науки связаны с именами В. В. Виноградова, Й. Л. Вайсгербера, Ю. Н. Караулова, В. В. Воробьева, В. И. Карасика, Г. И. Богина, О. Б. Сиротининой и др. Представим сжатое обобщение работ названных ученых.

Понятие языковой личности, по мнению многих ученых, является одним из важнейших в русле антропоцентрической парадигмы. Например, Т. В. Кочеткова отмечает, что с 90-х гг. ХХ в. «языковая личность становится стержневым системообразующим филологическим понятием. Большинством исследователей в настоящее время оно оценивается как интегративное, послужившее началом нового этапа в развитии языкознания - антрополингвистики» [15, с. 15]. Думается, что основная идея антропоцентрического подхода в языкознании базируется на понимании человека, его мировоззрения и ценностных ориентиров через познание его языка, т.е. внимание ученых, работающих в русле антропоцентрической парадигмы, приковано прежде всего к феномену языковой личности и ее проявлениям в различных коммуникативных ситуациях.

В 60-х гг. ХХ в. известный неогумбольдтианец Лео Вайсгербер обращается к понятию языковой личности. Он опирался на идеи В. фон Гумбольдта, которые заключаются в неразрывности связи человека с родным языком. B исследовании «Die sprachliche Personlichkeit» ученый рассматривает языковую личность через призму родного языка, к которому эта личность относится [3].

Обращение к исследованию данного понятия в отечественной лингвистике связано с именем В. В. Виноградова, который употребил термин «языковая личность» в публикации «О художественной прозе». Ученый подошел к понятию языковой личности в ходе исследования языка художественной литературы: «... если признать, что не только элементы речи, но и композиционные приемы их сочетаний, связанные с особенностями словесного мышления, являются существенными признаками языковых объединений, то структура литературного языка предстает в гораздо более сложном виде, чем плоскостная система языковых соотношений Соссюра. А личность, включенная в разные из этих «субъектных» сфер и сама включающая их в себя, сочетает их в особую структуру. В объектном плане все сказанное можно перенести и на parole, как сферу творческого раскрытия языковой личности» [4]. Ученый рассмотрел две ипостаси художественной языковой личности - личность автора и личность персонажа. Кроме того, он отталкивался от понимания языковой личности как национальной личности. Таким образом, анализируя данное понятие на материале художественной прозы, В. В. Виноградов считал, что за каждым текстом стоит языковая личность, в большей или в меньшей степени владеющая богатством языка.

В дальнейшем понятие «языковая личность» стало объектом научно-теоретического осмысления таких известных ученых, как Г. И. Богин, Ю. Н. Караулов, В. В. Воробьев, В. И. Карасик.

В трактовке В. В. Воробьева, «Личность - средоточие взаимосвязи культуры и языка, диалектики их развития. Поэтому о личности можно говорить только как о языковой личности, как о воплощенной в языке» [6]. Из приведенного определения можно заключить, что ученый обратил внимание на прагматический аспект языковой личности, который находит свое отражение в способности к рациональному использованию языковых ресурсов для достижения цели в коммуникативном акте.

В. И. Карасик подошел к вопросу о типах языковой личности с точки зрения межкультурного общения и выделил типы модельных языковых личностей современной России: криминальная личность, «новый русский», телевизионный ведущий. Для криминальной личности характерны специфическая интонация (манерное растягивание речи, тюремный жаргон («братан», «наезд» и т.п.). «Новый русский», по словам ученого, изъясняется «ярко и безвкусно с помощью приблизительных номинаций и уголовного жаргона». Третий тип телевизионный ведущий - противопоставлен криминальной личности и «новому русскому». По мнению В. И. Карасика, представители этого типа отличаются высокой степенью интеллекта, соблюдением языковых норм, склонностью к тонкому юмору и иронии. Типы модельных языковых личностей, выделяемые В. И. Карасиком, отражают социально-политическую ситуацию 90-х гг. в России [12].

Классификация Е. Ю. Коробковой создана на основе изучения речевого поведения личности с позиции психолингвистики. Исследователь предлагает выделять три типа языковых личностей: конфликтную, центрированную и кооперативную [16]. Конфликтная языковая личность, в свою очередь, подразделяется на два подтипа: речевой агрессор и речевой манипулятор. Основная тактика конфликтного типа языковой личности построена на неуважительном отношении к собеседнику, использовании агрессии, сарказмов. 
Следующий тип - центрированная языковая личность - в беседе слышит только то, что хочет слышать. Как правило, такой тип склонен к неоправданному возвышению своей личности и, по мнению, Е. Ю. Коробковой, в коммуникативной ситуации может проявлять себя чересчур эгоистично.

Центрированный тип подразделяется на активно-центрированный и пассивно-центрированный. Языковая личность активно-центрированного типа реагирует только на то, что ей интересно. Представители пассивно-центрированного типа замкнуты в себе, речь таких людей имеет низкую прагматическую направленность.

Кооперативный тип языковой личности Е. Ю. Коробкова подразделяет на два подтипа: кооперативный конформист и кооперативный актуализатор. Человек, относящийся к первому подтипу, как правило, в беседе занимает нейтральную позицию, соглашаясь с мнением собеседника. Языковые личности кооперативных актуализаторов проявляют интерес к речи собеседника и акцентируют внимание на отдельных словах, фразах [16].

В понимании В. И. Карасика, «языковая личность - это закрепленный преимущественно в лексической системе базовый национально-культурный прототип носителя определенного языка, составляемый на основе мировоззренческих установок, ценностных приоритетов и поведенческих реакций» [12, с. 19]. Трактовка исследователя основывается на осмыслении лексического уровня как доминирующего в структуре языковой личности.

Изучение вторичной личности всегда с проблемой определения единичного и общего, и уникального, индивидуального и в объекте исследования.

Языковая личность, по словам Г. И. Богина, это человек, готовый «производить речевые поступки, создавать и принимать произведения речи» $[1$, c. 3]. Ученый разработал модель языковой личности, в которой индивидуум предстает как носитель «языковых способностей, умений, готовностей». Некоторые ученые отмечают, что понимание языковой личности в трактовках Й. Л. Вайсгербера, В. В. Виноградова, В. В. Воробьева, В. И. Карасика, Г.И. Богина недостаточно полно отражает суть изучаемого понятия и систематизированное представление о нем в современной лингвистике.

В последние годы в языкознании активно начал употребляться термин - речевой портрет, который соотносится с понятием языковая личность [5, 25-26]. Антропоцентрическая парадигма предполагает, что необходимо учитывать все факторы и условия, связанные с субъектом речемыслительной деятельности. В языковой личности содержится «соотношение личности со структурой и функциями речевой деятельности, с одной стороны, и языком, как главной «образующей» образа мира человека, с другой» [20, с. 19].

Взаимообусловленность данных терминов прослеживается и в трехуровневой модели языко- вой личности, которую предложил Ю. Н. Караулов, включающую следующие уровни:

1. Вербально-семантический (владение естественным языком).

2. Когнитивный (понятия, концепты каждой языковой личности, идеи, систему ценностей).

3. Прагматический (цели, интересы, мотивы, установки и интенции языковой личности) [3; 12].

Данную модель Ю. Н. Караулов предложил для анализа структуры сформировавшейся языковой личности. Отметим, что это всеобъемлющее понимание термина «языковая личность» и его структуры, поэтому его трактовка понятия по праву считается ведущей в лингвистике.

Стоит отметить, что ученым выделен еще нулевой уровень, к которому относится обычное владение родным языком на бытовом уровне. В нем учитывается количество лексических единиц, а также умение правильно использовать вербальные знаки в соответствии с нормами. Предложенная Ю. Н. Карауловым трехуровневая модель языковой личности используется в когнитивной лингвистике, психолингвистике, дискурсивном анализе, социолингвистике и персонологии.

Идеи Ю. Н. Караулова были развиты другими исследователями, которые полагают, что «функциональная модель языковой личности (т.е. ее речевой портрет)» $[15$, с. 4] включает следующие уровни:

1) Лексикон языковой личности (отражение владения человеком лексико-грамматическим фондом языка, анализ языковых единиц, которыми пользуется конкретная языковая личность).

2) Тезаурус языковой личности (языковая картина мира, отражающаяся в речевом портрете при употреблении особой лексики, излюбленных разговорных формул).

3) Прагматикон (коммуникативные роли, мотивы, цели, интенциий, руководящие личностью в процессе коммуникации).

Более крупной единицей анализа, чем конкретная языковая личность признается понятие «тип языковой личности». Как мнению К. Ф. Седова, «одна из наиболее насущных задач, которые стоят перед современной антропоцентрической лингвистикой, - создание типологии языковых личностей, способной отражать индивидуальные особенности речевого поведения носителей языка» $[23$, c. 3].

На основании речевой культуры индивида выделяют носителей элитарной речевой культуры, среднелитературной, фамильярно-разговорной, литературно-разговорной, просторечной, народноречевой, профессионально-ограниченной [9].

А. Н. Большова предлагает классификацию языковых личностей, созданную на основе психологической типологии К. Г. Юнга. «В основе предлагаемых нами лингвопсихологических таксономий - тенденция коммуниканта использовать зна- 
ковые структуры, коррелирующие с психологическими переменными и характеризующие вербальное поведение». Данная классификация включает следующие типы.

- Метасимволическая языковая личность. Демонстрирует интуитив-нологический психотип, в психологии квалифицируется как мыслитель теоретик.

- Эмпатическая языковая личность. Демонстрирует интуитивно-эмоциональный психотип, в психологии квалифицируется как эстетическая художественная натура.

- Фактографическая языковая личность. Демонстрирует сенсорно-планирующий психотип, в психологии квалифицируется как мыслительпрактик.

- Репрезентативная языковая личность. Демонстрирует сенсорно-созерцательный психотип, в психологии квалифицируется как прагматическая художественная натура

Автор классификации отмечает, что в ней «два лингвопсихологических типа опираются на интуитивистскую основу (метасимволическая языковая личность и эмпатическая языковая личность), два на сенсорную (фактографическая языковая личность и репрезентативная языковая личность), что отражает самую большую разницу между людьми» [2, c. $48-50]$.

Интересной представляется классификация, предложенная Н. В. Орловой, которая выделяет три типа языковых личностей [22].

К фатическому типу относятся люди, стремящиеся к сокращению дистанции во взаимоотношениях с коммуникантами, к установлению и поддержанию контакта на должном уровне. «Фатические личности обычно игнорируют или ослабляют информативную сторону дискурса: для них важнее само общение, а не сообщение, обмен какой-либо информацией. Поэтому в речевом плане, в выборе жанров речевого общения и т.п. фактические языковые личности предпочитают стиль дружеского общения» [https://docplayer.ru/35210340-Yazykovaya-lichnost-v-kommunikativnom-prostranstve-diskursa.html].

К рационально-аналитическому типу относятся люди, которые обычно мотивируют свою оценку речевой ситуации и ее участников, используют объективную манеру речи. , аргументативный стиль, рассуждение с отсутствием внимания к эмоциональной стороне речи.

Эстетический тип «характерен безразличием к нормативному аспекту речевой коммуникации, игнорированием адресата, вниманием к языковой форме, ориентацией на свой внутренний мир и свои переживания. Жанровый репертуар составляют стихи, сентенции, лозунги. Активно используется языковая игра» [22].

Несколько иначе классифицируют типы языковых личностей И. Н. Горелов и К. Ф. Седов, хотя выделяемые им типы в целом соотносятся с типами языковых личностей, выделенными Н. В. Орловой.
Их классификация основывается на анализе речевого поведения языковой личности в ситуации конфликта. Отличия в коммуникативном поведении, по мнению исследователей, определяются индивидуально-личностными характеристиками говорящего: типом темперамента, воспитанием, уровнем образования и т.п. Ученые выделяют три типа языковой личности - инвективный, рационально-эвристический и куртуазный. Основу каждого типа составляет доминирующая стратегия (инвективная, рационально-эвристическая и куртуазная) в речевом поведении языковой личности в конфликтной ситуации.

Инвективная стратегия конфликтного поведения демонстрирует пониженную семиотичность: коммуникативные проявления здесь выступают отражением эмоционально-биологических реакций.

Рационально-эвристическая стратегия речевого поведения в ситуации конфликта опирается на рассудочность, здравомыслие. Негативные эмоции в этом случае выражаются косвенным, непрямым способом.

Куртуазная стратегия, наоборот, отличается повышенной степенью семиотичности речевого поведения, которая обусловлена тяготением говорящего к этикетным формам социального взаимодействия [11]. Изучая структуру языковой личности, И. Н. Горелов и К. Ф Седов подчеркивают, что человек строит свою речевую деятельность, используя готовые коммуникативные единицы, поэтому он нередко прибегает к использованию клише, схем, штампов.

Таким образом, можно констатировать, что термин «языковая личность успешно закрепился в современном языкознании. Множество его толкований и обилие различных классификаций доказывают тот факт, что в целом они соотносятся друг с другом, дополняют и подробнее характеризуют особенности конкретных языковых личностей. Рассмотрев трактовки понятия языковая личность от его становления до наших дней, можно заметить, как понятие расширялось: изменился предмет изучения: теперь это не только язык, но и мировоззренческие установки, поведенческие реакции.

\section{ЛИТЕРАТУРА}

1. Богин Г. И. Обретение способности понимать: Введение в герменевтику. Калинин, 1986. 357 с.

2. Большова А. Ю. Лингвопсихологическая типология языковых личностей // Филологические науки. Вопросы теории и практики, Тамбов: Грамота, 2015. Вып. 5(47): в 2-х ч. Ч. І. C. 47-52. URL: http://www.gramota.net/materials/2/2015/ 5-1/8.html (дата обращения: 25.07.2018).

3. Вайсгербер Й. Л. Родной язык и формирование духа. М., 2004. 232 с.

4. Виноградов В. В. Опыт риторического анализа // О художественной прозе. М., 1980. С. 120-146.

5. Власкова М. В. Языковая личность, ее структура: некоторые мнения и оценки // Вестник Вятского гос. ун-та, 2009. T. 2. Вып. 4. URL: http://cyberleninka.ru/article/n/yazykovaya-lichnost-eyo-struktura-nekotorye-mneniya-i-otsenki

6. Воробьев В. В., Хайруллина Р. Х. Национальная языковая личность как лингвокультурологический феномен // 
III Фирсовские чтения. лингвистика в XXI в.: междисциплинарные парадигмы / Междунар. научно-практ. конф. Москва, 14-15 ноября 2017 г. М: РУДН. 2017. С. 144-154.

7. Воробьев В. В. Фаткуллина Ф. Г. Интернациональная языковая личность в лингвокультурном пространстве. Уфа: РИЦ БашГУ, 2017. 203 с.

8. Голубева И. В. Опыт создания коллективного речевого портрета: автореф. дис. ... докт. филол. наук. Краснодар: КубГУ, 2002. 45 с.

9. Гольдин В. Е., Сиротинина О. Б. Русский язык и культура речи. М.: Логос, 2003. 280 c.

10. Горелов И. Н., Седов К. Ф. Основы психолингвистики. М.: Лабиринт, 2001. 304 с.

11. Иванцова Е. В. О термине «языковая личность»: истоки, проблемы, перспективы исследования // Вестник Томского гос. ун-та. Филология, 2010. Вып. 4(12). С. 24-31.

12. Карасик В. И. Языковой круг: личность, концепт, дискурс. Волгоград, 2002. 477 с.

13. Караулов Ю. Н. Русский язык и языковая личность. М.: Издательство ЛКИ, 2006. 264 с.

14. Касимханова А. Ф. Языковая личность регионального телеведущего в контексте телевизионного дискурса: дис. ... канд. филол. наук. Уфа, 2015. 24 с.

15. Китайгородская М. В., Розанова Н. Н. Русский речевой портрет. Фонохрестоматия. М.: Наука, 1995. 128 с.

16. Коробкова Е. Ю. Наша речь. Типы языковой личности // URL: http://metaslov.blogspot.ru/2012/05/blog-post_20.html

17. Кочеткова Т. В. Проблема изучения языковой личности носителя элитарной речевой культуры (обзор). URL:
http://portal.tpu.ru/SHARED/e/ELENNOV/four/Tab2/Kochet kovaTV.pdf

18. Кубрякова Е. С. Эволюция лингвистических идей во второй половине XX в. (опыт парадигмального анализа) // Язык и наука конца ХХ в. М., 1995. С. 144-238.

19. Кун Т. Структура научных революций. М.: АСТ, 2009. 310 с.

20. Леонтьев А. А. Основы психолингвистики. М.: Смысл, 1997. 287 с

21. Маслова В. А. Лингвокультурология. М.: «Академия», 2001. 208 c.

22. Орлова Н. В. Коммуникативная ситуация - речевой жанр - языковая личность (на мат-ле «Книги отзывов и предложений») // Жанры речи. Саратов: Колледж, 1999. Вып. 2. С. 227-236. URL: http://www.studfiles.ru/preview/ 3304463/page:21/

23. Седов К. Ф. О жанровой природе дискурсивного мышления языковой личности // Жанры речи. Межвуз. сб. науч. тр. Саратов, 1997. С. 3-26.

24. Соссюр Ф. де. Курс общей лингвистики // Труды по языкознанию. М.: Прогресс, 1977. 696 с.

25. Фаткуллина Ф. Г. Проблемы изучения полилингвальной языковой личности // Современные проблемы изучения башкирского и других родных языков в Республике Башкортостан и других регионах Российской Федерации. Уфа РИЦ БашГУ, 2017, С. 380-384.

26. Языковая личность в коммуникативном пространстве дискурса // URL: https://docplayer.ru/35210340-Yazykovayalichnost-v-kommunikativnom-prostranstve-diskursa.html

Поступила в редакичию 30.08.2018 2. 


\title{
LINGUISTIC PERSONALITY AS AN OBJECT OF LINGUOPERSONOLOGY
}

\author{
(C) L. R. Shamsutdinova
}

Bashkir State University

32 Zaki Validi Street, 450076 Ufa, Republic of Bashkortostan, Russia.

Phone: +7 (347) 2727463.

Email: muliya2814@gmail.com

The aim of this article is to consider the phenomenon of the linguistic personality as the main object of linguopersonology. Linguopersonology is a modern scientific direction; linguistic personality in all its communicative diversity is the central object of its studies. The main attention in the article is paid to the specifics of the modern language personality, its formation, as well as to the analysis of existing classifications of this language phenomenon. The author of the article considered different typologies of linguistic personalities. Qualitative features were studied within the framework of three essential characteristics (verbal-semantic, cognitive, and pragmatic). The components of the linguistic personality (ideological, cultural, and personal) were singled out. The author considered the objective factors that can determine its character.

Keywords: anthropocentrism, linguoperersonology, paradigm, linguistic personality, typology, classification, communicative situation.

Published in Russian. Do not hesitate to contact us at bulletin_bsu@mail.ru if you need translation of the article.

\section{REFERENCES}

1. Bogin G. I. Obretenie sposobnosti ponimat': Vvedenie v germenevtiku [Obtaining the ability to understand: Introduction to hermeneutics]. Kalinin, 1986.

2. Bol'shova A. Yu. Filologicheskie nauki. Voprosy teorii i praktiki, Tambov: Gramota, 2015. No. 5(47): v 2-kh ch. Ch. I. Pp. 47-52. URL: http://www.gramota.net/materials/2/2015/5-1/8.html (data obrashcheniya: 25.07.2018).

3. Weisgerber I. L. Rodnoi yazyk i formirovanie dukkha [Native language and formation of spirit]. Moscow, 2004.

4. Vinogradov V. V. O khudozhestvennoi proze. Moscow, 1980. Pp. 120-146.

5. Vlaskova M. V. Vestnik Vyat-skogo gos. un-ta, 2009. Vol. 2. No. 4. URL: http://cyberleninka.ru/article/n/yazykovaya-lichnost-eyostruktura-nekotorye-mneniya-i-otsenki

6. Vorob'ev V. V., Khairullina R. Kh. III Firsovskie chteniya. lingvistika v XXI v.: mezhdistsiplinarnye paradigmy. Mezhdunar. nauchnoprakt. konf. Moscow: 14-15 noyabrya 2017 g. M: RUDN. 2017. Pp. 144-154.

7. Vorob'ev V. V. Fatkullina F. G. Internatsional'naya yazykovaya lichnost' v lingvokul'turnom prostranstve [International linguistic personality in the linguocultural space]. Ufa: RITs BashGU, 2017.

8. Golubeva I. V. Opyt sozdaniya kollektivnogo rechevogo portreta: avtoref. dis. ... dokt. filol. nauk. Krasnodar: KubGU, 2002.

9. Gol'din V. E., Sirotinina O. B. Russkii yazyk i kul'tura rechi [Russian language and culture of speech]. Moscow: Logos, 2003.

10. Gorelov I. N., Sedov K. F. Osnovy psikholingvistiki [Basics of psycholinguistics]. Moscow: Labirint, 2001.

11. Ivantsova E. V. Vestnik Tomskogo gos. un-ta. Filologiya, 2010. No. 4(12). Pp. 24-31.

12. Karasik V. I. Yazykovoi krug: lichnost', kontsept, diskurs [Linguistic circle: personality, concept, discourse]. Volgograd, 2002

13. Karaulov Yu. N. Russkii yazyk i yazykovaya lichnost' [Russian language and linguistic personality]. Moscow: Izdatel'stvo LKI, 2006.

14. Kasimkhanova A. F. Yazykovaya lichnost' regional'nogo televedushchego v kontekste televizionnogo diskursa: dis. ... kand. filol. nauk. Ufa, 2015.

15. Kitaigorodskaya M. V., Rozanova N. N. Russkii rechevoi portret. Fonokhrestomatiya [Russian speech portrait. Phonochrestomathy]. Moscow: Nauka, 1995.

16. Korobkova E. Yu. Nasha rech'. URL: http://metaslov.blogspot.ru/2012/05/blog-post_20.html

17. Kochetkova T. V. Problema izucheniya yazykovoi lichnosti nositelya elitarnoi rechevoi kul'tury (obzor). URL: http://portal.tpu.ru/SH ARED/e/ELENNOV/four/Tab2/KochetkovaTV.pdf

18. Kubryakova E. S. Yazyk i nauka kontsa XX v. Moscow, 1995. Pp. 144-238.

19. Kuhn T. Struktura nauchnykh revolyutsii [The structure of scientific revolutions]. Moscow: AST, 2009.

20. Leont'ev A. A. Osnovy psikholingvistiki [Basics of psycholinguistics]. Moscow: Smysl, 1997.

21. Maslova V. A. Lingvokul'turologiya [Linguoculturology]. Moscow: «Akademiya», 2001.

22. Orlova N. V. Zhanry rechi. Saratov: Kolledzh, 1999. No. 2. Pp. 227-236. URL: http://www.studfiles.ru/preview/3304463/page:21/

23. Sedov K. F. Zhanry rechi. Mezhvuz. sb. nauch. tr. Saratov, 1997. Pp. 3-26.

24. Saussure F. de. Kurs obshchei lingvistiki. Trudy po yazykoznaniyu. Moscow: Progress, 1977.

25. Fatkullina F. G. Sovremennye problemy izucheniya bashkirskogo i drugikh rodnykh yazykov v Respublike Bashkortostan i drugikh regionakh Rossiiskoi Federatsii. Ufa RITs BashGU, 2017, Pp. 380-384.

26. Yazykovaya lichnost' v kommunikativnom prostranstve diskursa. URL: https://docplayer.ru/35210340-Yazykovaya-lichnost-v-kommu nikativnom-prostranstve-diskursa.html 